\title{
PENGEMBANGAN COMPUTER BASED TESTING (CBT) SEBAGAI ALTERNATIF TEKNIK PENILAIAN HASIL BELAJAR
}

\author{
Novrianti \\ Fakultas Ilmu Pendidikan Jurusan Teknologi Pendidikan \\ Universitas Negeri Padang, Jl. Hamka Air Tawar, Padang \\ Email: ynovrianti@yahoo.com
}

\begin{abstract}
Abstrak:
Penelitian ini bertujuan untuk menghasilkan produk pelaksanaan evaluasi berbantuan komputer atau computer based testing (CBT) sesuai kriteria kelayakan media dan materi melalui validasi beberapa ahli dan uji coba produk. Model penelitian pengembangan ini adalah model prosedural dengan subjek penelitian 4 responden yang terdiri dari dua orang validator ahli media dan dua orang validator ahli materi dan 1 orang guru. Instrumen yang digunakan dalam penelitian ini adalah dokumentasi, format penilaian dengan kriteria yang meliputi penilaian aspek isi materi berupa tes pilihan ganda dan penilaian aspek media. Angket digunakan dalam pelaksanaan uji coba untuk melihat kemudahan bagi subjek coba menggunakan produk CBT. Data dianalisis secara deskriptif kuantitatif untuk mengetahui kualitas produk CBT. Hasil analisis menunjukkan bahwa produk CBT berada pada kategori sangat baik (89\%), untuk aspek ini termasuk dalam kategori sangat baik, dan dari aspek media termasuk kategori juga sangat baik. Hasil analisis berdasarkan uji coba produk juga berada pada kategori sangat baik. Hasil tersebut menunjukkan bahwa produk CBT ini layak digunakan sebagai media alternatif untuk memecahkan permasalahan pelaksanaan evaluasi pembelajaran.
\end{abstract}

\begin{abstract}
:
This research aimed at creating a product for conducting evaluation using computer or it is called computer based testing (CBT). It was made based on the appropriate characteristics of media and material, and was validated by some experts and by conducting a product trial. The model of this developmental research was a procedural model with 4 respondent, two experts of media validator, two experts of material validator, and one teacher. The instruments used in this research were documentation, evaluation format with the chriteria consisted of material content assessment in the form of multiple choice and assessment of media aspect. The questionnaire used in the trial is to see the easiness of the subjek to use CBT product. The data were analized quatitatively descriptive to find out the quality of the CBT product. The result showed that the CBT product was at the level of very good cathegory (89\%), and the media aspect was also in the very good cathegory. The result of the analysis on the product trial showed that CBT product was appropriate to be used as an alternatif media to solve the problem of conducting learning evaluation.
\end{abstract}

Kata kunci:

Evaluasi, computer based testing

SEBAGAI tenaga profesional, guru memegang peranan dan tanggung jawab penting dalam pelaksanaan program pembelajaran di kelas. Pada proses pembelajaran, guru 
dituntut untuk memiliki pengalaman, pengetahuan tentang siapa peserta didiknya, dan bagaimana menyampaikan ilmu dengan baik serta kemampuan dalam mengevaluasi.

Melalui evaluasi, guru dapat mengetahui tingkat ketercapaian pembelajaran. Dalam melakukan evaluasi hasil belajar siswa, sebaiknya tidak hanya mendasarkan penilaian secara langsung dari hasil belajar siswa dalam menjawab, tetapi juga memperhatikan faktor-faktor yang memengaruhinya. Menurut Anas Sudijono, terdapat beberapa faktor yang memengaruhi terjadinya kekeliruan dalam pengukuran atau evaluasi hasil belajar siswa, yaitu faktor alat pengukur, faktor evaluator, faktor peserta didik, dan faktor situasi. ${ }^{1}$ Oleh karena itu, seorang guru dituntut untuk memahami hakikat evaluasi dan memiliki kemampuan dalam melakukan evaluasi. Hasbullah Thabrany menulis:

Penyebab seseorang tidak dapat berkonsentrasi dapat dibagi menjadi 2 kelompok, yaitu gangguan dari dalam (internal) dan gangguan dari luar (eksternal). Gangguan dari dalam misalnya, tekad yang kurang kuat untuk belajar, sifat emosi, sifat mudah marah dan benci, haus, lapar, kurang sehat badan target kerja yang tidak realistis, masalah pribadi dengan pacar, guru atau orang tua. Gangguan dari luar misalnya suara gaduh, tidak tersedianya alat keperluan belajar, suasana kondisi belajar. ${ }^{2}$

Berdasarkan pendapat mengenai faktor yang memengaruhi keberhasilan belajar, disimpulkan dua faktor yang berasal dari internal dan eksternal siswa yang dapat memengaruhi pelaksanaan evaluasi dan berimbas kepada hasil belajar siswa. Dalam satu analisis menyebutkan, guru menghabiskan 20 sampai 30 persen waktu profesional mereka untuk menghadapi persoalan penilaian. ${ }^{3}$ Umumnya, guru menghabiskan banyak waktu untuk menghitung dan menjumlahkan setiap hasil ujian siswa. Artinya, banyaknya waktu untuk digunakan menilai, maka penilaian itu semestinya berlangsung dengan baik. ${ }^{4}$

Agar efektif dalam pelaksanaannya, sebaiknya guru menggunakan media pembelajaran sebagai alat bantu untuk melakukan penilaian seperti Computer Based Testing atau disingkat CBT. Menurut Van Der Linden yang dikutip oleh Santrock bahwa dengan kemajuan teknologi, praktik penilaian mungkin kelak akan berbeda dengan bentuk penilaian sekarang yang kebanyakan masih menggunakan pena dan kertas. ${ }^{5}$

Menurut James Mc Millan, penilaian bukan hanya pencatatan apa yang diketahui dan dapat dilakukan murid, tetapi juga memengaruhi pembelajaran dan motivasi mereka. Pelajar perlu mengerti pengetahuan yang diterima dan pendidik perlu mengetahui apakah mereka telah mengajarkan pengetahuan mereka dengan baik. Keduanya memerlukan umpan balik. CBT membantu untuk mempercepat pemenuhan kebutuhan umpan balik ini. ${ }^{6}$

Berdasarkan hasil wawancara dan observasi sementara yang penulis lakukan pada beberapa siswa kelas X (Sepuluh) Sekolah Menengah Atas (SMA) di kota Padang, diperoleh sejumlah informasi di antaranya; masih dilaksanakan ujian dengan menggunakan metode konvensional yakni pena dan lembar soal. Masih sering terja- 
dinya contek-mencontek antar sesama siswa, siswa kebingunan ketika harus berhadapan dengan lembaran soal untuk menjawabnya, padahal selama pembelajaran mereka lebih banyak praktik di laboratorium komputer. Ada juga siswa yang mengetahui dan memahami materi praktik, namun ketika menjawab soal di lembaran kertas ia menjadi lupa dan menjawab asal-asalan. Siswa sulit mengingat langkahlangkah dalam menjalankan sesuatu dan saat hal itu ditanyakan, maka mereka tidak bisa menjawab dengan tepat serta siswa tidak bisa melihat secara langsung skor yang dicapainya saat ujian.

Berdasarkan gejala-gejala yang ada, penulis melihat pelaksanaan tes di SMA belum optimal pada aspek perencanaan, proses, dan kemampuan mengembangkan alat pelaksanaan evaluasi. Untuk mengatasi masalah tersebut, diperlukan suatu alternatif pemecahan masalah. Salah satu solusi untuk permasalahan ini adalah dengan penggunaan CBT. CBT mampu mengemas soal ujian menjadi lebih efektif, disertai multimedia seperti grafis, klip video, dan pendekatan file suara dapat dimasukkan dalam batang pertanyaan, tanggapan atau umpan balik. Mengurangi biaya kertas dan dilengkapi dengan fasilitas scoring langsung serta layanan autorun. Dengan demikian, diharapkan mampu meningkatkan fungsi dan tujuan dari diadakannya sebuah tes hasil belajar.

Berdasarkan uraian latar belakang di atas, dapat dirumuskan permasalahan yaitu, bagaimana pengembangan tes hasil belajar menggunakan computer based testing (CBT) yang berkualitas sesuai dengan kriteria kelayakan media pada mata pelajaran TI \& K kelas X SMA .

\section{KAJIAN TEORI}

\section{Tes, Penilaian, Pengukuran, dan Evaluasi}

Menurut Zainal Arifin, tes merupakan suatu alat yang berisi serangkaian tugas yang harus dikerjakan atau soal-soal yang harus dijawab oleh peserta didik untuk mengukur suatu aspek prilaku tertentu. ${ }^{7}$ Adapun fungsi tes, menurut Sudijono adalah alat pengukur terhadap peserta didik dan juga sebagai alat pengukur keberhasilan program pengajaran. ${ }^{8}$ Dalam menyusun tes, terdapat ciri-ciri tes yang baik sehingga ketercapaian belajar siswa dapat di interpretasikan dengan optimal. Di antara ciri tes yang baik adalah:

1. Tes bersifat valid atau memilki validitas yang sesuai atau tepat.

2. Tes telah memiliki reliabilitas atau bersifat reliabel.

3. Tes besifat objektif atau bersumber dari materi pelajaran yang diberikan.

4. Tes bersifat praktis dan ekonomis. ${ }^{9}$

Selain itu, seorang evaluator juga harus memperhatikan prinsip-prinsip pengembangan tes agar fungsi tes dan tujuan pelaksanaannya dapat tercapai sesuai dengan yang diharapkan. Menurut Sudijono prinsip-prinsip dasar penyusunan tes hasil belajar, yaitu:

1. Tes hasil belajar harus dapat mengukur hasil belajar yang telah ditetapkan sesuai dengan tujuan instruksional; 
2. Butir-butir soal tes harus merupakan sampel yang merepresentasi populasi bahan pelajaran;

3. Bentuk soal yang harus dikeluarkan dalam tes harus dibuat bervariasi;

4. Tes harus didesain sesuai dengan kegunaannya untuk memperoleh hasil yang diinginkan;

5. Tes harus memiliki reliabilitas yang dapat diandalkan;

6. Tes di samping harus dapat dijadikan alat pengukur keberhasilan belajar siswa, juga harus dapat dijadikan alat untuk mencari informasi yang berguna untuk memperbaiki cara belajar siswa dan cara mengajar guru itu sendiri. ${ }^{10}$

\section{Computer Based Testing(CBT)}

CBT adalah sistem evaluasi berbantuan komputer yang bertujuan untuk membantu guru dalam melaksanakan evaluasi, baik penskoran, pelaksanaan tes maupun efektivitas dan efisiensi pelaksanaannya. Tes nantinya akan berbantuan media dan pelaksanaannya pun menggunakan komputer.

Menurut John Daintith, CBT merupakan penggunaan komputer untuk mengendalikan, baik digital maupun analog teknik pengujian dan evaluasi kualitas komponen dan produk. ${ }^{11}$ Selain itu, menurut AJ Romiszowski:

Computer Based Testing may (like CMI) be part of a CAI sistem, or may be a stand alone facility. Some Computer Based Testing facilities are no more than an item bank, which can be used to generate two or more tests of equivalent content and difficulty, to be used at different moments in conventional classroom. ${ }^{12}$

Sistem computer based testing (CBT) atau pelaksanaan evaluasi dengan berbantuan komputer merupakan turunan atau pengembangan sistem computer assisted instructional (CAI) atau pembelajaran berbantuan komputer yang dikhususkan pada bidang garapan evaluasi meliputi kumpulan-kumpulan soal dan proses penskoran otomatis, media audio, video dan interaktif serta autorun. Menurut Sri Lestari, CBT adalah suatu metode administrasi tes yang dilakukan secara elektronik dengan dicatat, dinilai, atau keduanya. ${ }^{13}$ CBT merupakan sistem penilaian berdasarkan komputer serta bagian dari cakupan Computer Assisted Instructional(CAI) yang dapat dilengkapi dengan audio, video, penskoran, dan layanan autorun.

Schreyer Institute, menyebut beberapa keuntungan menggunakan CBT dalam penilaian sebagai berikut:

1. Inclusion of multi-media; Graphics, short video clips or sound files can be included in question stems, responses or feedback.

2. Item format; CBT allows for item types that can't be processed by scanning paper bubble sheets, such as "check all that apply."

3. Reduce paper costs; Computer-based tests for large classes avoid what can be a substantial cost in producing paper tests.

4. Scoring; Many item types can be automatically scored. ${ }^{14}$

Beberapa keuntungan sistem CBT disebut di atas meliputi kemasan soal lebih menarik karena disampaikan secara multimedia, tidak menggunakan pena dan ker- 
tas, mengurangi biaya, uji penghitungan skor valid, menghemat waktu, lebih cepat dalam pengambilan keputusan sebagai hasil dari pelaksanaan tes. CBT dapat menggunakan software apapun dalam praktik atau penerapannya dengan ketentuan memenuhi kriteriasebagai tools atau alat pelaksana tes hasil belajar. Software yang penulis gunakan untuk pelaksanaan CBT ini adalah Macromedia Director MX 2004.

\section{Prosedur Menggunakan Computer Based Testing (CBT)}

1. Pengguna harus memastikan kelengkapan sarana \& prasarana pendukung pelaksanaan CBT, seperti: 1 unit PC (Personal Computer) untuk setiap siswa dan dilengkapi dengan CD (Compact Disk) CBT.

2. Soal dikemas dalam bentuk CD. kemudian dimasukkan kedalam $C D$ Room yang terdapat pada PC.

3. Soal akan langsung muncul seketika saat CD CBT dimasukkan kedalam CDRoom (Autorun Service).

4. Soal berupa tes obyektif bentuk multiple choice item (Pilihan Ganda)

5. Baca dan silahkan dilihat terlebih dahulu video demo serta petunjuk umum dan khusus penggunaan CBT.

6. Soal akan berlanjut setelah pengguna menjawab soal sebelumnya, tanpa bisa mengulanginya kembali. Sebagai upaya mengurangi kegiatan untuk saling mencontek.

7. Soal berjumlah 20 butir yang terdiri dari pilihan ganda

8. Skor soal akan langsung muncul setelah pengguna menjawab soal ke 20 (automatic scoring)

9. Masing-masing soal diberikan durasi waktu untuk menjawab selama 1 menit, jika melebihi 1 menit maka akan muncul peringatan bahwa waktu telah habis.

\section{METODOLOGI PENELITIAN}

Penelitian ini adalah penelitian pengembangan atau research and development (R\&D). Penelitian pengembangan menggunakan model prosedural pengembangan produk dengan pola sebagai berikut:

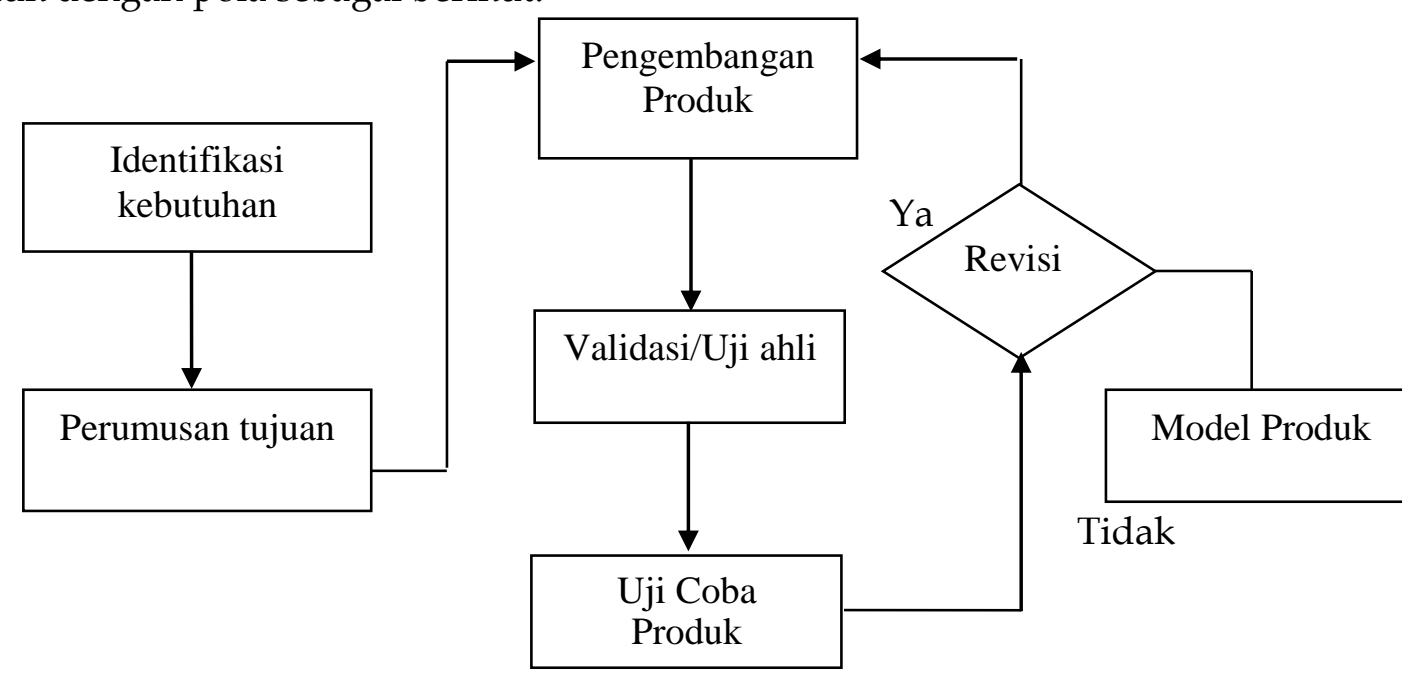


Prosedur pengembangan tes hasil belajar menggunakan CBT adalah metodologi pengembangan multimedia versi Luther terdiri dari enam tahap, yaitu: concept (pengonsepan), design (pendesainan), material collecting (pengumpulan materi), assembly (pembuatan), testing (pengujian), distribution (pendistribusian). ${ }^{15}$

Validator yang terlibat dalam penelitian ini berjumlah 4 orang, 2 validator ahli media dan 2 validator ahli materi. Variabel yang diteliti adalah kualitas produk dari segi media dan kualitas materi atau tes oleh ahli materi.

Pada uji coba produk ini yang menjadi subjek coba adalah siswa kelas X SMA. Subjek coba akan dilibatkan dalam rangka untuk melihat kemudahan penggunaan produk CBT. Instrumen untuk mengumpulkan data dalam penelitian ini adalah: (1) dokumentasi berupa catatan-catatan, kritik, saran dan masukan, baik itu dari ahli media maupun ahli materi, (2) format penilaian menggunakan format respons lima poin dari skala Likert. Format penilaian digunakan untuk mengukur indikator program yang berkenaan dengan aspek media dan materi, dan (3) angket, untuk mengumpulkan data dalam rangka melihat kemudahan penggunaan produk Computer Based Testing (CBT).

Pengumpulan data dilakukan dengan cara pemberian dokumentasi dan format penilaian secara langsung kepada produk. Setelah data diperoleh, selanjutnya adalah menganalisis data menggunakan Analisis Deskriptif Kuantitatif.

\section{HASIL PENELITIAN DAN PEMBAHASAN}

\section{Hasil Penelitian}

Berdasarkan pengolahan data dengan menggunakan SPSS 15 untuk melihat validitas dan reliabilitas tes, maka diperoleh sejumlah informasi bahwa dari 60 butir soal yang diberikan, sebanyak 34 butir soal valid dan 26 butir soal lainnya tidak valid. Hasil uji reliabilitas tesnya berada pada kategori reliabilitas tinggi dengan nilai 0.729. Nilai ini berada pada range $0,60 \leq \mathrm{r} 11<0,79$.

Hasil perolehan penilaian aspek isi dengan kriteria kebenaran konsep, kedalaman materi, dan penulisan dari 2 validator diperoleh jumlah rerata sebesar 4,8 dengan persentase sebesar $96 \%$. Hasil review ahli media untuk tampilan produk CBT dari aspek media, di antaranya tampilan isi, animasi dan tampilan button, diperoleh jumlah rerata sebesar 4,1 dan persentase $83 \%$. Berdasarkan 2 responden ahli materi, diperoleh penilaian dari aspek isi tentang kebenaran konsep diperoleh skor rerata 5 (100\%), dengan kategori sangat baik. Sedangkan dari penyajian materi diperoleh skor rerata 4,6 (93\%) dengan kategori sangat baik, serta dari aspek penulisan diperoleh skor rerata $4,8(97 \%)$ dengan kategori sangat baik. Dengan demikian, skor secara keseluruhan untuk aspek isi diperoleh rerata 4,8 (96\%) dengan kategori sangat baik.

Uji coba produk merupakan upaya untuk melihat kualitas produk CBT. Kualitas produk, khususnya mengenai kemudahan menggunakan produk CBT (user friendly) menurut subjek coba atau pengguna. Seperti yang diungkapkan oleh Nusa Putra bahwa tujuan dilaksanakannya uji coba terhadap suatu produk pengembangan adalah untuk melihat titik lemah dan kekurangan produk agar dapat diperbaiki dan 
lebih disempurnakan. ${ }^{16}$ Berdasarkan uji coba produk, CBT diperoleh nilai rata-rata sebesar 4,7 dengan persentase kemudahan penggunaan produk CBT sebesar $94 \%$ pada kategori sangat baik.

Berdasarkan hasil analisis data disimpulkan bahwa secara keseluruhan aspek isi dan materi pada produk CBT termasuk kategori sangat baik, namun pada aspek tertentu ada yang perlu direvisi supaya produk CBT ini lebih layak digunakan.

\section{Pembahasan}

Produk Computer Based Testing (CBT) digunakan sebagai media evaluasi, sehingga melalui evaluasi berbantuan komputer diharapkan siswa dan guru dapat melaksanakan tes lebih efektif dan efisien serta membantu kemudahan penskoran. Menurut Anas Sudijono, terdapat beberapa faktor yang memengaruhi terjadinya kekeliruan dalam pengukuran atau evaluasi hasil belajar siswa yaitu, faktor alat pengukur, faktor evaluator, faktor peserta didik, dan faktor situasi. ${ }^{17}$ Berdasarkan pendapat ini, maka pelaksanaan evaluasi harus memperhatikan faktor-faktor yang memengaruhinya agar evaluasi yang dilaksanakan dapat memberikan informasi mengenai ketercapaian pembelajaran.

Selain itu, Hasbullah Thabrany yang dikutip oleh Djamarah mengemukakan bahwa:

Penyebab seseorang tidak dapat berkonsentrasi dapat dibagi menjadi 2 kelompok, yaitu gangguan dari dalam (internal) dan gangguan dari luar (eksternal). Gangguan dari dalam misalnya, tekad yang kurang kuat untuk belajar, sifat emosi, sifat mudah marah dan benci, haus, lapar, kurang sehat badan target kerja yang tidak realistis, masalah pribadi dengan pacar, guru atau orang tua. Gangguan dari luar misalnya suara gaduh, tidak tersedianya alat keperluan belajar, suasana kondisi belajar. ${ }^{18}$

Berdasarkan pendapat ini, diperlukannya suatu upaya yang dapat mengatasi permasalahan yang ada melalui pelibatan media baik dari segi pembelajaran maupun sebagai alat bantu evaluasi yang diharapkan dapat memperkecil atau mengatasi sebagian besar dari permasalahan pada pelaksanaan evaluasi. Menurut Miarso bahwa media pembelajaran adalah:

Segala sesuatu yang digunakan untuk menyalurkan pesan serta dapat merangsang pikiran, perasaan, perhatian, dan kemauan peserta didik sehingga dapat mendorong terjadinya proses belajar yang disengaja, bertujuan, dan terkendali. ${ }^{19}$

Evaluasi akan lebih baik bila dapat merangsang siswa untuk berpikir dan mengingat materi pelajaran yang telah dipelajari sebelumnya. Artinya, pelaksanaan evaluasi sebaiknya dapat mengukur keterlibatan pola berpikir kolaboratif siswa, baik dari pemahaman teori maupun praktik. Penggunaan CBT dalam pelaksanaan evaluasi dapat memberikan rangsangan berpikir kepada siswa, baik dari pemahaman teori maupun praktik sehingga lebih efektif dalam penskoran serta memperkecil kemungkinan terjadinya kekeliruan baik dari faktor alat pengukur, faktor evaluator, faktor peserta didik, dan faktor situasi. Data uji produk CBT menunjukkan CBT memiliki 
kelayakan sebagai produk membantu guru, khususnya dan siswa umumnya untuk dapat melaksanakan evaluasi berupa tes secara lebih mudah karena dukungan animasi, gambar, musik, foto, video tutorial, dan tes yang menarik sehingga siswa dapat melihat secara langsung skor yang dicapainya melalui display komputer.

Meskipun demikian, produk CBT bukan merupakan sumber evaluasi yang utama dalam proses mendapatkan hasil belajar, melainkan aplikasi yang diharapkan dapat membantu memecahkan permasalahan yang ada ketika evaluasi dilaksanakan, baik sebagai media evaluasi alternatif dan pelengkap maupun sebagai bahan pengayaan. Melalui produk CBT ini, diharapkan evaluasi TI \& K menjadi lebih baik dan sesuai dengan tujuan yang diharapkan.

\section{SIMPULAN DAN SARAN}

\section{Simpulan}

1. Computer Based Testing (CBT) adalah suatu teknik pelaksanaan ujian pada mata pelajaran TI \& K SMA kelas X yang dikemas dalam bentuk media ini termasuk ke dalam kategori sangat baik, dengan kualitas tampilan program termasuk dalam kategori sangat baik.

2. Berdasarkan uji coba produk CBT yang dilaksanakan pada 6 subjek coba, produk ini termasuk pada kategori sangat baik.

3. Berdasarkan hasil deskripsi data uji ahli, produk CBT ini layak digunakan sebagai salah satu alternatif pelaksanaan ujian dalam mata pelajaran TI \& K kelas X SMA.

\section{Saran}

1. Dalam pengembangan produk CBT ini sebaiknya dilakukan oleh tim pengembang yakni terdiri dari beberapa orang yang memiliki keahlian pada bidang tes dan pada bidang media agar hasil yang diperoleh berkualitas.

2. Bagi seorang pengembang atau guru, diharapkan meningkatkan pengetahuannya tentang komputer terutama mengenai desain, pemrograman, dan desain grafis dalam membuat produk CBT sehingga untuk masa yang akan datang dapat mengembangkan produk CBTuntu kujian yang lain.

3. Dari hasil penelitian yang telah dilakukan, produk CBT ini layak digunakan oleh guru mata pelajaran TI \& K kelas X SMA dan sederajat.

\section{CATATAN AKHIR:}

1. Anas Sudijono, Pengantar Statistik Pendidikan, Jakarta: RajaGrafindo Persada, 2009, h. 42.

2. Syaiful Bahri Djamarah, Psikologi Belajar, Jakarta: Rineka Cipta, 2008, h. 21.

3. John Santrock, Psikologi Pendidikan, Edisi Kedua, Jakarta: Kencana, 2008, h. 638.

4. Ibid., h. 638.

5. Ibid., h. 648.

6. Ibid., h. 638.

7. Zainal Arifin, Evaluasi Pembelajaran, Bandung: Rosda, 2011, h. 3.

8. Anas Sudijono, op. cit., h. 67. 
9. Ibid., h. 93.

10. Ibid., h. 97.

11. John Daintith, "Computer-Aided Testing." A Dictionary of Computing, 2004, Retrieved May 31, 2011 from Encyclopedia.com: http://www.encyclopedia.com/doc/1O11-computeraided-testing.html, diakses tanggal 8 agustus 2011.

12. A.J. Romiszowski, The Selection and Use of Intructional Media, New York: Kogan Page Publishing, 1988, h. 306.

13. Sri Lestari, Computer Based Testing, from http://srifisika.wordpress.com/2010/07/30/computer-based-testing-cbt-2/, diakses pada tanggal 6 juni 2011.Sri Lestari (2010)

14. Schreyer Institute for Teaching Excellence, 2011.

15. Iwan Binanto, Multimedia Digital: Dasar Teori dan Pengembangannya, Yogyakarta: Penerbit ANDI, 2010, h. 259.

16. Nusa Putra, Research \& Development: Penelitian dan Pengembangan: Suatu Pengantar, Jakarta: Rajawali Press, Nusa Putra, 2011, h. 171

17. Anas Sudijono, op. cit., h. 42.

18. Syaiful Bahri Djamarah, op. cit., h. 21.

19. Yusufhadi Miarso, Menyemai Benih Teknologi Pendidikan, Jakarta: Pustekom Diknas dan Kencana, 2004, h. 458.

\section{DAFTAR PUSTAKA}

Arifin, Zainal. Evaluasi Pembelajaran. Bandung: Rosda, 2011.

Binanto, Iwan. Multimedia Digital (Dasar Teori dan Pengembangannya). Yogyakarta: Penerbit ANDI, 2010.

Daintith, John. "Computer-Aided Testing": A Dictionary of Computing, 2004. Retrieved May 31, 2011 from Encyclopedia.com: http://www.encyclopedia.com/doc/1O11-computeraidedtesting.html.

Djamarah, Syaiful Bahri. Psikologi Belajar. Jakarta: Rineka Cipta, 2008.

Lestari, Sri, Computer Based Testing. From http://srifisika.wordpress.com/2010/07/30/computer-based-testing-cbt-2/.

Miarso, Yusufhadi. Menyemai Benih Teknologi Pendidikan. Jakarta: Pustekom Diknas dan Kencana, 2004.

Putra, Nusa. Research \& Development Penelitian dan Pengembangan: Suatu Pengantar. Jakarta: Rajawali Press, 2011.

Romiszowski. The Selection and Use of Intructional Media. New York: Kogan Page Publishing, 1988.

Santrock, John. Psikologi Pendidikan. Edisi Kedua, Jakarta: Kencana, 2008.

Schreyer Institute for Teaching Excellence, 2011.

Setyosari, Punaji, Metode Penelitian Pendidikan dan Pengembangan, Jakarta: Kencana Prenada Media Group, 2010. 